\title{
The Pharmacists Attributes in Advising Patients in Independently Owned Maltese Pharmacies
}

\author{
Alina Cernasev ${ }^{1}$, Ronald Hadsall ${ }^{1}$, Maria Cordina ${ }^{2}$ \\ ${ }^{1}$ Department of Pharmaceutical Care \& Health Systems, College of Pharmacy, University of Minnesota, \\ Minneapolis, USA \\ ${ }^{2}$ Department of Clinical Pharmacology and Therapeutics, Faculty of Medicine and Surgery, \\ University of Malta, Msida, Malta \\ Email: cerna004@umn.edu, hadsa001@umn.edu, maria.cordina@um.edu.mt
}

Received 4 March 2014; revised 6 April 2014; accepted 28 April 2014

Copyright (C) 2014 by authors and Scientific Research Publishing Inc. This work is licensed under the Creative Commons Attribution International License (CC BY). http://creativecommons.org/licenses/by/4.0/ (c) 7 Open Access

\section{Abstract}

Objectives: To determine the influence of pharmacists on customers who have to decide between Over the Counter products in independently owned Maltese pharmacies. Methods: 20 managing pharmacists in independently owned Maltese pharmacies were interviewed. The interviews were recorded, transcribed verbatim and the data were coded. The main categories and subcategories were extracted and interrelated by using the grounded theory of action approach. Key findings Pharmacists dedicate time to ensure the right OTC is received by their patients. Before recommending an OTC medication the pharmacists ask key questions, which help them determine if an OTC is appropriate for the patient. The Maltese pharmacists engage their patients in a discussion before recommending an OTC product. In order to ensure that the patients are following their advice, pharmacists use different techniques. Whenever the patient might want to purchase an OTC, which could interfere with their medication regimen or might not be appropriate from the age point of view, then pharmacist intervenes accordingly. Each pharmacist offered specific examples how they convince their patients to purchase the correct medication. The pharmacists provided specific examples how they decide to select a specific OTC medicine and what type of questions were asked before taking a decision. In order to ensure their patients have the best access to the health care, many pharmacists embraced other roles and services, such as measuring and monitoring the blood pressure and glucose levels, determining the correct weight management product. Conclusions: The analyzed data highlight that Maltese community pharmacists play an important role in counseling patients on their choice of OTC products. The analysis has also identified some useful counseling techniques, which has been used by pharmacists for prescription medications. However, the Maltese pharmacists use these counseling techniques on a larger scale. It seems likely that many pharmacists are embracing more additional roles to ensure their population receives the best clinical ser- 
vices. Before dispensing an OTC medication, pharmacists use their clinical knowledge.

Keywords

Pharmacists, Independent Maltese Pharmacies, Over the Counter Medications, Safety, Counseling

\section{Introduction}

The Maltese Archipelago is made of three inhabited islands: Malta, Gozo and Comino situated in the center of Mediterranean, $80 \mathrm{~km}$ southeast of Sicily. The size of Malta is $315 \mathrm{~km}^{2}$, which makes it the smallest member state of the European Union. The population as of July 2011 was estimated at 408,000. Therefore, it makes one of the most density populated countries worldwide. The national languages are Maltese and English [1]. In addition tourists at peak periods could easily double the population size.

Malta has 213 independent pharmacies. This corresponds to just under 2000 citizens per pharmacy.

However, ownership is not restricted to pharmacists and anyone can own one or more pharmacies.

Consequently, most of the graduates are employed in independent Pharmacies. Being part of the European Union, the profession is self-regulating and is subject to European Union Directives.

As the increase in health care demands, community pharmacists are engaged in multiple tasks in Malta such as counseling for prescription and non-prescription medications, filling and dispensing prescriptions, management and creating orders. It has to be emphasized that the pharmacists' roles have changed over the years [2] [3]. The pharmacist's role has evolved from the traditional one-where pharmacists used to compound and dispense medications - to a more complex one where the pharmacists play a key role in the pharmaceutical care of patients [2] [4]. This concept was first introduced by Helper and Strand in 1990, which was defined as "pharmaceutical care” [3]. The pharmaceutical care concept has transformed the pharmaceutical world. This change was observed in the following decade when the curriculum of the pharmacy schools in the developed countries adopted it as a philosophy and standard of care for their patients [5] [6].

Over the Counter products (OTCs) are defined as pharmaceutical products, which contain an active ingredient, which does not require a prescription [7] [8]. All OTC medications are displayed behind the counter in Mata and can only be purchased from a pharmacy. In order to obtain an OTC product, the patient must interact with the pharmacist/pharmacy staff. This could be seen as a benefit to the consumers since as the literature mentions, some people might be inclined to overuse or misuse these medicines [7] [8].

OTC products have been extensively studied around the world, given their importance in the process of selfcare. Customers might ask for the pharmacists' opinion about OTC medications. In principle the pharmacist's role is to maximize the patient's understanding and involvement in the OTC decision. The goal of interaction between the pharmacist and the patient from the pharmacists' point of view is to obtain a positive clinical outcome with a reduced economic impact on the patient [6].

Patients could be readily confused by the excessive availability of information through television, radio, pharmacy displays and press advertisements. Due to the abundance of information provided, some customers could use irrationally the OTC medications to treat their condition [9]. There are times when individuals might not have time to read the package insert, and the information presented on the box is too complex for them or they are attracted by the large displays located in the pharmacy. Additionally, if that OTC medicine is intended to be administered to a child, then the parent has to dedicate more time to understand clearly the instructions [10].

This present study aims to investigate the influence of the pharmacist on patients when they have to decide between the large choices of available OTC products. The objectives of this present study were:

1) To determine the influence of pharmacists on customers who have to decide between OTC products;

2) To identify the rationale behind the pharmacists' advice;

3) To identify the existence of barriers to self-care from the pharmacists point of view.

\section{Methods}

\subsection{Participants}

A letter was sent to the managing pharmacist of all community pharmacies in Malta in which the study explain- 
ing and inviting them to participate. Those who were willing to participate were asked to contact the investigators through an email address provided. Twenty pharmacists responded to this study. The study received approval from the University of Malta Research Ethics Committee and was conducted during the summer of 2012. Since the principal investigator is a student at the University of Minnesota, the study also received approval from the Institutional Review Board (IRB), Minnesota, USA.

\subsection{Data Gathering}

Since English is one of the official languages in Malta, a face to face interview with the practicing pharmacist was selected as the main method. The reasons for choosing a face to face interview were the advantage of using open-ended questions. For example, if there were any problems understanding or interpreting the questions, then by observing and listening to the answers, the meaning could be determined. Furthermore, more probing and elaborated questions could be asked. The interviewee had the option to be recorded or not. If the person declined to be recorded, it was explained that the interview might take longer since the answers would have to be written down. The recording was being done with the goal of obtaining the nuance of the information. During these interviews, the interviewer took special care not be judgmental and there were no positive and negative feelings towards the pharmacist's opinion provided. The same interview structure and questions were used for all participating pharmacists irrespective if they were pharmacy owners or employees. The guidelines for the interview questions and techniques were based on [11] [12].

Individual interviews were used in preference to focus groups or online surveys because this method was more efficient and time-effective from both parts points of view. All the interviews took place in the pharmacy where the participant was practicing, while the principal investigator visited that pharmacy. The time and day of the interview was chosen by the participant. All of the pharmacies were easily accessible by public transportation and most of the pharmacies were located in the urban area of Malta.

\subsection{Interview Structure}

The interview questions were divided into two categories. The first part focused on pharmacists' background and demographics, while the second part concentrated on pharmacist's decision making process and the perception of their clientele especially with regards to barriers to the self-care medication.

Interview Questions:

1) For how long have you practiced pharmacy?

2) For how long have been working in this pharmacy?

3) What makes your pharmacy unique from the OTC point of view?

4) How much time do you spend with a customer, who is undecided regarding OTC products?

5) How do you decide if one OTC product is the best option?

6) What kind of information do you need before taking a decision between one OTC and another?

7) How often are you asked for advice?

What is the primary barrier to self-care medications?

\section{Data Analysis}

Interviews were recorded, and transcribed verbatim by the principal investigator. A total of 28 pages of data were manually coded. The interpretation of data was done by using grounded theory approach [13]. The grounded theory approach is to create hypothesis, which are interpreted in the context. Consequently, the opinion statements were divided into 10 main groups. Each group was subcategorized into two, three or four subcategories. Then, each category and subcategory was interrelated which lead to five main themes. A summary of the Process of extracting the main themes is presented in Figure 1.

In order to remove identifiable details each interviewed pharmacist was assigned a letter and a number. For example if the pharmacist was the owner $(\mathrm{O})$, while the employees were assigned $(\mathrm{E})$.

\section{Results}

The participants $(n=20)$ were practicing pharmacists whose mean working experience was $15.8(S D \pm 11.4$ years; range 1 - 40 years). Seven of the participants were men. Eight of the participants were employees. The 
information can be found in Table 1. The independent pharmacies visited have been located in the different parts of the Island, including Gozo. Five main themes were extracted from the data; however this paper addresses three themes, since the other two have been presented as a poster elsewhere [14].

\subsection{Rational Underlying the Decision Making Process for the Pharmacist}

All interviewed pharmacists stated that they have to gather information about the age, onset of the symptoms, medication history, and other illnesses before taking a decision. Pharmacists' responses varied, however before making a decision, all the pharmacists interviewed took into account drug-drug interactions and some mentioned food-drug interactions. Therefore, safety and efficacy were very important criteria before taking a decision. The cost of the OTC products has been mentioned lastly by some pharmacy owners.

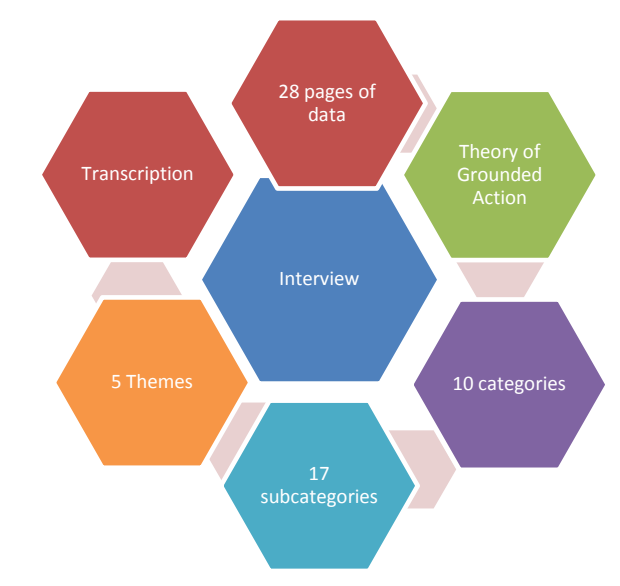

Figure 1. Process of extracting the main themes.

Table 1. Demographic characteristics of respondents.

\begin{tabular}{|c|c|c|c|c|c|}
\hline Pharmacy (P) & $\begin{array}{l}\text { Pharmacists } \\
\text { per pharmacy }\end{array}$ & Gender & $\begin{array}{c}\text { Years of practicing } \\
\text { pharmacy }\end{array}$ & $\begin{array}{l}\text { Years of practicing in } \\
\text { the current location }\end{array}$ & Interviewee code \\
\hline $\mathrm{P} 1$ & 1 & Male & 9 & 9 & (O1) \\
\hline P4 & 2 & Female & 36 & 36 & $(\mathrm{O} 2)$ \\
\hline P3 & 1 & Female & 3 & 3 & (O3) \\
\hline P4 & 1 & Female & 15 & 7 & (E1) \\
\hline P5 & 1 & Female & 20 & 20 & $(\mathrm{O} 4)$ \\
\hline P6 & 1 & Male & 16 & 16 & (O5) \\
\hline P7 & 1 & Female & 4 & 4 & (E2) \\
\hline P8 & 1 & Male & 24 & 16 & (O6) \\
\hline P9 & 1 & Female & 20 & 8 & (O7) \\
\hline P10 & 1 & Female & 2 & 2 & (E3) \\
\hline P11 & 2 & Male & 18 & 18 & (O8) \\
\hline P12 & 2 & Male & 16 & 16 & (E4) \\
\hline P13 & 1 & Male & 22 & 22 & (O9) \\
\hline P14 & 2 & Female & 15 & 15 & (E5) \\
\hline P15 & 1 & Female & 20 & 9 & (E6) \\
\hline $\mathrm{P} 16$ & 1 & Female & 30 & 24 & (O10) \\
\hline P17 & 1 & Female & 1 & 1 & (E7) \\
\hline P18 & 1 & Female & 3 & 3 & (E8) \\
\hline P19 & 2 & Female & 40 & 40 & (O11) \\
\hline P20 & 3 & Male & 4 & 2 & (O12) \\
\hline
\end{tabular}


"I always ask about the symptoms and duration and get all the medication history... then, I go to the active ingredient and decide if the active ingredient is indicated from pharmacological point of view for that patient or not. Then, ... I recommend. There are many products with the same active ingredient. The cost is the last option when I decide for an OTC, but you know... I am the owner; I have to think of the margin profit for the product." (O5)

"I always use my pharmacological knowledge.... So... I look at the active ingredient... I talk to the patient... and get all the medication history, what they are taking... and the symptoms history... Then... I know the contraindications of the active ingredient... And based on all this information I dispense an OTC or not... If one product is contraindicated... I go to the next class of medications, which can be used in that patient..." (E2)

"I check what they are taking... Get all the medication history. Get the symptoms. I ask about what they are eating... you know there are so many drug-food interactions... It's very common to have wine on the table for lunch, dinner. So, I repeat a few times and write it down on the box, no alcohol with this medication, ... this includes OTC as well... You must be very careful with OTC... especially... in Malta... because a few glasses of wine might not be ok... with an OTC... so... tell them a few times and reinforce... Write it on the box, underline the word... NO alcohol... until you make sure, they understood... because you know what happens... if you tell them don't take it with alcohol, they will ignore it... but if you write it down in the box... they will listen... otherwise, they can't say you didn't say... it's underlined on the box... So... after I check the drug interactions, medication history, symptoms, food-drug interaction, I give the best medication at the cheapest possible price." (E4)

\subsection{Pharmacists' Techniques Regarding Counseling}

Counseling patients was seen as being crucial for the profession of pharmacy. Each pharmacist used different strategies to engage the patients in a discussion and ensuring that the advice offered was followed properly.

Most of the Maltese independent community pharmacies had only one pharmacist per shift. However, there were situations when two or even three pharmacists were present in the pharmacy and each one played a different role. Actually, the presence of another pharmacist was explained by the interviewee that one pharmacist could dedicate more time counseling, while the other was doing other duties.

A deeper pharmacist-patient relationship was mentioned by some participants especially when the pharmacist had been in working in the locality for a long time such as over twenty or even forty years. Consequently, the pharmacist had been interacting with two or even three generations of customers belonging to one family. By being familiar with the patients, it was much easier to offer proper advice.

In order to ensure the patients understood the directions correctly, the pharmacists had to use simplistic words or a higher tone. Others were using analogies and dedicated more of their time to offer the required advice. Some pharmacists mentioned that a number of elderly patients need more attention from the counseling point of view. In order to ensure the older patients understand and follow the advice properly, some participants discussed different strategies. For example, writing the information down on the box, or using louder voice, or asking them to repeat back.

"I take my time with patients, counseling; make sure they understand the advice I give them, by asking to repeat back what I said. First, I explain to them, then I ask them to repeat in order to confirm. If you explain and ask did you understand, I do not know what they understood. But by asking them to explain back, you confirm what they understood... There are elderly people who cannot understand directions. The problem with the older patients is that they have Alzheimers or dementia or are senile and forget to take the medications. So I set pill boxes, even for OTC products. They get confused easily and I try to write the directions simply on the OTC box." $(\mathrm{O} 1)$

"I always give them advice... how to take it, ..., I take my time to explain how to take it, when to take it... I use simple words... I have to explain very well because people cannot understand pharmacy language... You know... some words are very complicated... So I use as simple language as I can...” (O5)

"There is another pharmacist working here, so I take my time explaining and giving advice. Some people are old, so they come and ask how to take it even if I have already explained to them before, ... But I take my time whenever is necessary... I spend as much as possible to make sure the OTCs are used properly... so, they know how to take it and when, ... and I am happy as a pharmacist because I am asked for advice and have more patient interaction... advising-is the only job satisfaction...” $(\mathrm{O} 10)$ 


\subsection{Additional Services Provided by the Pharmacists}

Despite the fact the Maltese Archipelago is small, the pharmacy's individualization could be observed. As some participants stated the individualization from the OTC point of view of the pharmacy has been achieved through various factors. Some pharmacies carry more products such as weight management products or diabetic foot products. Some interviewed pharmacists emphasized that they took additional roles such as offering diabetes screening, glucose monitoring, blood pressure monitoring. According to the interviewees these additional services were valued by their patients because the pharmacists can help them to have better control of their health care. All these roles created a better relationship with the patient, where patients had an increased appreciation for the pharmacists' professional role and advice. A number of pharmacists mentioned that patients come to their pharmacy because they regard them as the primary care provider.

"I also provide glucose tests, cholesterol; blood pressure (BP) readings. In the case of the BP readings, they have a card. In the case of BP-is very hard to determine since compliance is a problem; because they might not feel any symptoms. They decide to decrease the dose or stop taking the medications. My job is to convince them they need the medications and asking them to come back once per week or twice per month for regular BP monitoring and according to the results, I recommend dosage optimization. Especially during summer when it's very hot in Malta, I recommend to monitor BP more often and also keep an eye on the dosage, to make sure they don't lower the dosage too much." $(\mathrm{O} 1)$

"I offer many products, which cannot be found in any other pharmacy. For example, I have many products for weight loss, or skin products... I create a personal relationship with my patients and they come back because they trust my advice and I am honest with them.... when they ask me about weight loss products, I weigh them and calculate the BMI... then... I decide if they need a product or not... I always take their medication history to make sure they qualify for that product... sometimes..., I want to know their underlying condition... I recommend seeing a Dr." $(\mathrm{O} 7)$

"Some of the patients are older and they come to the pharmacy and ask me: What shall I do? Look... what happened... I always advise them, depending on the symptoms... or they show me their wound and want my opinion... So, I explain how to clean it and if it is necessary I refer them to a physician. They come to the pharmacy and consider the pharmacist as a reference point. They are our friends..." (O10)

\section{Discussion}

The results from this study emphasized the changing role of the pharmacist in independent community pharmacies in Malta. Counseling customers was one important role for the profession of the pharmacy, which was addressed in great detail especially when an OTC product was purchased. Safety and efficacy were the most important criteria before the participants were taking a decision. The participants of this study pointed out different barriers, which prevented the customers obtaining an achievable outcome that are not addressed in this discussion.

The analysis of the themes obtained from this present study emphasizes the crucial role played by the pharmacists by being the primary care providers. As has been mentioned by most of the pharmacists interviewed, their role evolved from an apothecary based one-where they used to compound and dispense medicines - to a more complex one where pharmacists are seen to be the primary care provider. This primary care provider role has been exemplified by many international studies and this current one reinforces the literature [2] [3].

All the participants in this study and the main themes extracted from the data described an expanding role of the pharmacist. Some of the pharmacists responsibilities involved identifying the main medication problem, distinguish between the major side-effects produced by the medicines and solving the problem. These roles have been discussed by Nkansah in a literature review and this current study can bring more support to the literature [15], by reporting their expanding attributes. In order to exemplify their attributes and roles, some participants presented the health care services offered to the community they serve. For example, some pharmacies offered additional services such as diabetes screening, monitoring blood pressure, weight loss advising and vaccines. This expanded role reinforced what you found in a study conducted in Hong-Kong [16]. Subsequently, pharmacists around the world are embracing new roles, which make them a unique link in the pharmacist-customer-doctor relationship [5].

One of the main themes extracted from the interviews was that pharmacists were major players in advising. In order to transmit their message effectively, some of the participants mentioned the usage of the Indiana Health 
Service model, which employed open-ended questions and asked the client to repeat what they understood. This model was often used in the USA pharmacies because it allowed the pharmacist to obtain a better understanding of the patient's chief complaints and reviewed the main points. This has been interpreted by Lewis et al., as a model of communication, which was not limited to prescription medications. On the contrary, this Indiana model was widely used by pharmacists in the self-care counseling [17]. Obviously, this present study has shown that the Indiana model has been used beneficially worldwide. Additionally, a Finnish study has shown how patients can benefit from the pharmaceutical advice when they are counseled by the pharmacists. Clearly, these counseling episodes were crucial especially in the OTC area [18].

However, as it was pointed out by the participants the level of understanding the advice was crucial for the patient' safety. The type of language employed by the participants was clearly exemplified in the results. In order to avoid confusion and to ensure the patients understood the instructions correctly, most of participants were using plain and simplistic words and some were using analogies. As Chew has shown in her study, sometimes clinical staffs were employing screening questions, which would help to identify those individuals with lower level of health literacy [19]. This approach had also been used by some Maltese participants. Ngoh et al. found that, if the client understood the directions of that specific medication and the expected outcome, then that person would be more likely compliant [20]. Moreover, as the participants stated during their interviews and also pointed out in the Ngoh study, patients with lower levels of education tended to use visual and or oral tools to remember the pharmacists' advice [20].

If the clientele is older, then the participants in this current study mentioned the usage of various techniques in order to ensure all the recommendations were followed. It is generally known that, older populations had decreased cognitive functions such as understanding, hearing and memory. Consequently, some older patients had a lower ability to recall all the information provided by the pharmacist and the information provided on the label [21]. In the case when the pharmacist encountered older patients, as some participants stated, the pharmacist employed different approaches to make sure the clients would not forget all the important details received during counseling. One approach was to ask the patient to repeat what they understood in regards how to take that specific OTC product. Some of these techniques have been reported by the Sansgiry et al. and this present study confirms their usage [22].

How do pharmacists take decisions when there is a plethora of OTC products? Overall, all the participants in this present study stated that before taking a decision they would have to take into consideration the safety of their clients. These answers strengthen the previous conclusion obtained in a study conducted in Northern Ireland. After evaluating the pharmacists' attitudes and opinions and the reasons for taking a decision about OTC medications, both studies - the Northern Ireland one and this present study-reached the same conclusion, that safety was the major contributing factor when making decisions about self-care medicines [23]-[25].

A study conducted in Scotland by Walker et al., investigated the psychological variables influences on the community pharmacists. This study suggested that when recommending OTC medications the pharmacists' beliefs were not the main factors in the decision making process.

The sampled participants all emphasized that the price was not the most important criteria when a decision was made. On the contrary, the symptoms of the condition and the how long will take to relieve the symptoms were very important criteria. However, in less affluent areas of Malta, some pharmacists interpreted the price as a barrier because some customers could not afford the recommended OTC product.

\section{Limitations}

This study had some limitations, since it had 20 participants, where the conclusions might not be generalized to all Maltese pharmacists. However, these sampled participants represent $10 \%$ of the Independent pharmacies, which would be an appropriate representation.

\section{Conclusions}

The study illustrated that in Malta community pharmacists play an important role in counseling the patients on the large choice of OTC products available. Different counseling techniques are employed by the pharmacists and their usage depends on the age of their patients and the level of education of the patients.

In order to ensure the right OTC medications are used, the pharmacists are engaging the patients in a discussion where they are asking key questions. The focus of these discussions is the safety of the population, efficacy 
of the product and guidance offered to the patients if other OTC products have to be used.

The Maltese pharmacists' roles have expanded by providing services to the target population. These additional services, such as blood pressure monitoring or vaccines administrations, offer them a direct contact with the patients and interactions with other health providers such as doctors.

Further studies conducted for a longer period of time and involving more pharmacists are recommended.

\section{References}

[1] Zammit, V. (2011) Malta History \& Tradition. 1st Edition, BDL Publishing, San Gwann.

[2] Worley, M.M., et al. (2007) Pharmacists’ and Patients’ Roles in the Pharmacist-Patient Relationship: Are Pharmacists and Patients Reading from the Same Relationship Script? Research in Social and Administrative Pharmacy, 3, 47-69.

[3] Helper, C.D. and Strand, L.M. (1990) Opportunities and Responsibilities in Pharmaceutical Care. American Journal of Hospital Pharmacists, 47, 543-553.

[4] McCann, L.M., Haughey, S.L., Parsons, C., Lloyd, F., Crealey, G., Gormley, G.J. and Hughes, C.M. (2012) A Patient Perspective of Pharmacist Prescribing: “Crossing the Specialisms-Crossing the Illnesses”. Health Expectations, Epub Ahead of Print. http://dx.doi.org/10.1111/hex.12008

[5] Farris, K.B., Fernandez-Llimos, F. and Benrimoj, S.I. (2005) Pharmaceutical Care in Community Pharmacies: Practice and Research from around the World. Annals of Pharmacotherapy, 39, 1539-1541. http://dx.doi.org/10.1345/aph.1G049

[6] Cipolle, R., Strand, L.M. and Morely, P.C. (2012) Pharmaceutical Care Practice: The Patient-Centered Approach to Medication Management Services. McGrow-Hill Medical, New-York.

[7] Mifusd, J. (2011) Abuse of OTC and Prescribed Drugs: Popping Pills for Thrills? Journal of the Malta College of Pharmacy, 17, 16-20.

[8] Sheen, C.L. and Colin-Jones, D.G. (2001) Review Article: Over-the-Counter Drugs and the Gastrointestinal Tract. Aliment Pharmacology Therapeutics, 15, 1263-1270. http://dx.doi.org/10.1046/j.1365-2036.2001.01042.x

[9] Faerber, A.E. and Kreling, D.H. (2012) Now You See It. Now You Don’t: Fair Balance and Adequate Provision in Advertisements for Drugs before and after the Switch from Prescription to Over-the-Counter. Health Communication, 27, 66-74. http://dx.doi.org/10.1080/10410236.2011.569001

[10] Yin, H.S., Mendelsohn, A.L., Nagin, P., van Schaick, L., Cerra, M.E. and Dreyer, B.P. (2013) Use of Active Ingredient Information for Low Socioeconomic Status Parents’ Decision-Making Regarding Cough and Cold Medications: Role of Health Literacy. Academic Pediatrics, 13, 229-235. http://dx.doi.org/10.1016/j.acap.2013.01.004

[11] Dillman, D.A. (2007) Mail and Internet Surveys. 2nd Edition, New York John Wiley \& Sons, New York.

[12] Grosshans, W. and Chelimsky, E. (1991) Using Structured Interviewing Techniques. United States General Accounting Office, Washington DC.

[13] Glasser, B.G. and Srauss, A.L. (1967) The Discovery of Grounded Theory: Strategies for Qualitative Research. Adeline Publishing Company, Chicago.

[14] Cernasev, A., Freitas, E., Hadsall, R. and Cordina, M. (2013) Pharmacists Approach in Enhancing Self-Care through the Use of over the Counter Medication in Independent Community Pharmacies in Malta. Proceedings of 73rd International Congress of FIP, Dublin, Poster Number 47.

http://www.postersessiononline.eu/aula_poster.asp?congreso=375133693\&grupo=todos\&buscar=si\&texto=Alina $\% 20$ Cernasev\&texto_libre=Alina\%20Cernasev\&tipo=autor

[15] Nkansah, N., Mostovetsky, O., Yu, C., Chheng, T., Beney, J., Bond, C.M. and Bero, L. (2010) Effect of Outpatient Pharmacists' Non-Dispensing Roles on Patient Outcomes and Prescribing Patterns. Cochrane Database Systematic Reviews, Article ID: CD000336.

[16] You, J.H. Wong, F.Y., Chan, F.W., Wong, E.L. and Yeoh, E.K. (2011) Perception on the Role of Community Pharmacists in Self-Medication and Self-Care in Hong Kong. BMC Clinical Pharmacology, 25, 11-19.

[17] Lewis, R.K., Lasack, N.L., Lambert, B.L. and Connor, S.E. (1997) Patient Counseling-A Focus on Maintenance Therapy. American Journal of Health Systems Pharmacy, 54, 2084-2098.

[18] Kansanaho, H., Isonen-Sjölund, N., Pietilä, K., Airaksinen, M. and Isonen, T. (2002) Patient Counselling Profile in a Finnish Pharmacy. Patient Education and Counselling, 47, 77-82. http://dx.doi.org/10.1016/S0738-3991(01)00180-X

[19] Chew, L.D., Bradley, K.A. and Boyko, E.J. (2004) Brief Questions to Identify Patients with Inadequate Health Literacy. Family Medicine, 36, 588-594.

[20] Ngoh, L.N. (2009) Health Literacy: A Barrier to Pharmacist-Patient Communication and Medication Adherence. Journal of the American Pharmacist Association, 49, e132-e146. 
[21] Morrell, R.W., Park, D.C. and Poon, L.W. (1990) Effects of Labeling Techniques on Memory and Comprehension of Prescription Information in Young and Old Adults. Journal of Gerontology, 45, 166-172. http://dx.doi.org/10.1093/geronj/45.4.P166

[22] Sansgiry, S.S., Chanda, S. and Shringarpure, G.S. (2007) Impact of Bilingual Product Information Labels on SpanishSpeaking Adults' Ability to Comprehend OTC Information. Research in Social and Administrative Pharmacy, 3, 410425. http://dx.doi.org/10.1016/j.sapharm.2006.12.001

[23] Hanna, L.A. and Hughes, C. (2012) The Influence of Evidence-Based Medicine Training on Decision-Making in Relation to Over-the-Counter Medicines: A Qualitative Study. International Journal of Pharmacy Practice, 20, 358-366. http://dx.doi.org/10.1111/j.2042-7174.2012.00220.x

[24] Hanna, L.A. and Hughes, C. (2011) Public’s Views on Making Decisions about Over-the-Counter Medication and Their Attitudes towards Evidence of Effectiveness: A Cross-Sectional Questionnaire Study. Patient Education Counselling, 83, 345-351.

[25] Hanna, L.A. and Hughes, C. (2010) “First, Do No Harm”: Factors That Influence Pharmacists Making Decisions about Over-The-Counter Medication: A Qualitative Study in Northern Ireland. Drug Safety, 33, 245-255.

http://dx.doi.org/10.2165/11319050-000000000-00000 